\title{
Adverse drug reactions in paediatric patients in a tertiary care hospital in India: a prospective observational single centre study
}

\author{
T. V. S. Divyalasya ${ }^{1}$, Vasundara Krishnaiah ${ }^{2}$, H. T. Yashoda ${ }^{2}$, Pundarikaksha H. P. ${ }^{2}$, \\ B. L. Kudagi ${ }^{1}$, Ramamohan Pathapati ${ }^{1}$
}

${ }^{1}$ Department of Pharmacology, Narayana Medical College, Nellore, Andhra Pradesh, India ${ }^{2}$ Department of Pharmacology, Kempegowda Institute of Medical Sciences, Bangalore, Karnataka, India

Received: 16 July 2016

Accepted: 13 August 2016

*Correspondence to:

Dr. Divyalasya Tanguturi

Venkata Sai,

Email: divyalasya@gmail.com

Copyright: () the author(s), publisher and licensee Medip Academy. This is an openaccess article distributed under the terms of the Creative Commons Attribution NonCommercial License, which permits unrestricted noncommercial use, distribution, and reproduction in any medium, provided the original work is properly cited.

\begin{abstract}
Background: Adverse drug reactions (ADRs) are a major source of concern in adult and paediatric population. Monitoring ADRs in children is vital as they differ from adults in pharmacokinetic and pharmacodynamics responses. Strict ethical guidelines in clinical trials result in extrapolation of data from studies done in adults. Further, ADRs reported in adults do not predict those in children. Incidence of ADRs in children is $2.9 \%$ emphasizing the need for systematic monitoring. Studies at institutional level can generate valuable data among paediatric population. Hence, the current study was taken up to assess the clinical pattern of ADRs, their causality, severity and preventability.

Methods: This is a prospective observational single centre study. Suspected cases of ADRs were collected and assessed for the clinical pattern, causality, severity and preventability factors along with gender-wise distribution.

Results: A total of 118 ADRs were reported in our study. Most of the ADRs $(46.67 \%)$ occurred below 1 year of age with male preponderance $(53.4 \%)$. Skin was the most common organ involved $(91.5 \%)$. Majority $(78.8 \%)$ of ADRs were due to anti-infectives for systemic use $(\mathrm{J})$. Vaccines were the most commonly implicated agents $(55.9 \%)$ followed by antibiotics $(22.9 \%)$. Severe reaction like DRESS syndrome was reported due to antiepileptics (including levetiracetam) requiring hospitalisation. Majority of ADRs were probable $(92.4 \%)$, moderate $(73.7 \%)$ and definitely preventable $(61 \%)$.

Conclusions: A wide range of ADRs are possible in paediatric population. Adequate knowledge about ADRs is essential and caution has to be exercised even while prescribing drugs which are considered safe in children.
\end{abstract}

Keywords: Antiepileptics, DRESS syndrome, Levetiracetam, Paediatrics, Pharmacovigilance, Vaccines

\section{INTRODUCTION}

Adverse drug reactions (ADRs) are one of the important causes of morbidity and mortality in both adults and children. ${ }^{1}$ As defined by WHO, "ADR is a response to a drug that is noxious and unintended, and occurs at doses normally used in man for the prophylaxis, diagnosis or therapy of disease, or for modification of physiological function". "Pharmacovigilance (PV) is the science and activities relating to the detection, assessment, understanding and prevention of adverse effects of pharmaceutical products". ${ }^{2}$ Incidence of ADRs causing hospital admission in children ranges from $0.4-10.3 \%$ and their occurrence in hospitalised children is $0.6-16.8 \%$. The overall incidence of ADRs in children is $2.9 \% .^{3}$ Statistics reflect the magnitude of problem necessitating the need for early detection, treatment and reporting of ADRs.

WHO-UNICEF report 2006 quotes, "children are not small adults when taking a drug". ${ }^{4}$ Children are a highly varied group of different physiologies. Drug pharmacokinetics and pharmacodynamics alter with respect to various stages of growth and development from neonates to adolescents. E.g., metabolism of paracetamol is by sulfate conjugation in infants and children, whereas 
primarily by glucuronide conjugation in adults. ${ }^{4}$ Additionally, certain ADRs are exclusively seen in children, e.g. chloramphenicol induced gray baby syndrome in preterm neonates and certain others are more common like dystonia with metoclopramide. ${ }^{5}$ Such responses cannot be elicited in adults. Thus, paediatric population is a spectrum rendering drug use childspecific. $^{4}$ Furthermore, stringent ethical guidelines in clinical trials exclude paediatric population resulting in lack of clinical drug safety data in children. Data from adults is usually extrapolated to paediatric age group making them vulnerable to ADRs. ${ }^{1,6}$

In India, children account for a large part of general population and around half the proportion of children suffer from malnutrition, which affects drug pharmacokinetics and increases the frequency of ADRs. Therefore, detailed information regarding ADRs is essential to ensure appropriate prescription practices. Large cohort studies and systematic reviews from various European countries, Shanghai etc. are published thus far but very few from Indian subcontinent. Fewer studies have analysed the preventability of ADRs. Hence, the present study was taken up to generate valuable data at an institutional level to assess clinical pattern, causality, severity and preventability of ADRs.

\section{METHODS}

This prospective observational study was conducted in Department of Pharmacology, Kempegowda Institute of Medical Sciences and Research Centre, Bangalore, for 18 months to assess the clinical pattern, spectrum, causality, severity and preventability of ADRs reported among inpatients and outpatients of Paediatrics department. Patients aged 0-18 years of either gender with suspected ADRs to pharmaceutical products, vaccines and neutraceuticals were included in the study. Drug reactions to blood, blood products and medicines of alternative system like Ayurveda, Homeopathy, Unani etc. or due to deliberate/unintentional overdose or error in prescribing/dispensing were excluded. Study was taken up after obtaining institutional ethics committee approval and written informed consent from parents/legal representatives of the subjects. Awareness and motivational programme on ADRs was conducted. Consecutive cases of suspected ADRs were identified and included for analysis. Suspected ADRs were reported verbally or through the ADR reporting form (yellow form) and Central Drug Standard Control Organization (CDSCO) ADR reporting form. Detailed history including present and past medical, personal, family and drug/allergy history was documented for every case. A thorough clinical evaluation and scrutiny of data was done to assess clinical pattern, extent, severity and duration of reactions to detect any predisposing or underlying disease/pathological factors, and to assess organ system involvement. Any untoward event was labelled as ADR after a detailed discussion with the treating paediatrician. Pattern of reported ADRs was analysed for their clinical type and causative drugs. System organ class involved was analysed based on anatomical, therapeutic and chemical (ATC) classification, causality by WHO-UMC and Naranjo's causality assessment scale, severity by modified Hartwig scale and preventability by Modified Schumock and Thornton scale. ${ }^{7-11}$ Follow-up was done for certain and severe ADRs to assess the clinical progress and outcome.

\section{Statistical analysis}

Data obtained was analysed using descriptive statistics and ADRs were presented gender-wise. Non-normal data was expressed as median and interquartile range (IQR) for quantitative variables. MS Word and MS Excel were used to analyse and generate graphs and tables, wherever necessary. All multiple responses were reported in terms of percentage and total of such response is greater than sample size.

\section{RESULTS}

A total of 118 ADRs were reported in the study. Large number of ADRs was collected through active reporting; very few were reported spontaneously. The median age was 1.6 years $(0.75$ years in males, 3.6 years in females $)$ and IQR was 0.17 - 9 years $(0.17-4$ years in males, 0.17 11 years in females). The youngest was 2 days old and the oldest was of 18 years. Younger children developed more ADRs. Fifty five $(46.6 \%)$ children were between $0-1$ year with $32(50.8 \%)$ males and $23(41.8 \%)$ females. This was followed by $25(21.2 \%)$ among $1-5$ years, $18(15.3 \%)$ between 5-10 years, $10(8.5 \%)$ above 10 years. Sixty three $(53.4 \%)$ subjects were males and $55(46.6 \%)$ were females.

Patients presented with a wide range of ADRs, the commonest being local site reactions in 66 (55.9\%) children (Table 1). Most common organ system involved was skin in $108(91.5 \%)$ children (Table 2). Therapeutic class of suspected ADRs was analysed according to the ATC classification (level 1) and majority of ADRs were due to anti-infectives for systemic use (J) which also includes vaccines (Table 3). Table 4 presents the therapeutic class of drugs causing ADRs and vaccines were the most common in $66(55.9 \%)$ children.

Highest number of ADRs among vaccines was due to $\mathrm{DPT}+\mathrm{HepB}+\mathrm{HiB}$ in $36(54.5 \%)$ children $-25(60.9 \%)$ males, $11(44 \%)$ females followed by DPT + HepB and BCG in $12(18.2 \%)$, DPT in $4(6.1 \%)$, and DPT + HiB in 2 (3\%) children. ADRs observed were injection site reactions like pain, redness, warmth and swelling and other symptoms like excessive crying and refusal to feed. BCG additionally caused blister formation at injection site. It is prudent to notice that all $66(100 \%)$ children who received $\mathrm{DPT}+\mathrm{HepB}+\mathrm{HiB}$ developed local injection site reactions only $60(90.9 \%)$ developed fever and 54 $(81.8 \%)$ excessive crying and refusal to feed. Out of 12 BCG related reactions, only $2(16.7 \%)$ children developed fever (Table 1). 
Table 1: ADRs observed with gender-wise distribution and the causative drugs.

\begin{tabular}{|c|c|c|c|c|}
\hline ADRs & Males n (\%) & Females n (\%) & Total* n $(\%)$ & Causative drugs (n) \\
\hline $\begin{array}{l}\text { Injection site pain, } \\
\text { Local redness, } \\
\text { Injection site warmth, } \\
\text { Injection site swelling }\end{array}$ & $41(65.1)$ & $25(45.5)$ & $66(55.9)$ & $\begin{array}{l}\text { DPT+HepB+HiBpro (36), BCG (12), } \\
\text { DPT+HepB (12), DPT (4), DPT+HiB } \\
\text { (2) }\end{array}$ \\
\hline Fever & $39(61.9)$ & $21(38.2)$ & $60(50.8)$ & $\begin{array}{l}\text { DPT+HepB+HiBpro (36), } \\
\text { DPT+HepB (12), DPT (4), BCG (2), } \\
\text { DPT+HiB (2), Levetiracetam (2), } \\
\text { Lamotrigine (1), Phenytoin (1) }\end{array}$ \\
\hline $\begin{array}{l}\text { Excessive crying, } \\
\text { Refusal to feed }\end{array}$ & $39(61.9)$ & $15(27.3)$ & $54(45.8)$ & $\begin{array}{l}\text { DPT+HepB+HiBpro (36), } \\
\text { DPT+HepB (12), DPT (4), DPT+HiB } \\
\text { (2) }\end{array}$ \\
\hline Generalised skin rash & $18(28.6)$ & $25(45.5)$ & $43(36.4)$ & $\begin{array}{l}\text { Ranitidine (8), Ceftriaxone (5), } \\
\text { Amoxicillin-Clavulanic acid (4), } \\
\text { Cefadroxil (2), Ibuprofen (2), } \\
\text { Levetiracetam (2), Ondansetron (2), } \\
\text { Phenobarbitone (2), Phenytoin (2), } \\
\text { Vancomycin (2), Amoxicillin (1), } \\
\text { Carbamazepine (1), Cefixime (1), } \\
\text { Cefotaxime (1), Cefpodoxime (1), } \\
\text { Dicyclomine (1), Drotaverine (1), } \\
\text { Gentamicin (1), Lamotrigine (1), } \\
\text { Meropenem (1), Piperacillin- } \\
\text { Tazobactam (1), Prednisolone (1) }\end{array}$ \\
\hline Generalised pruritus & $15(23.8)$ & $19(34.5)$ & $34(28.8)$ & $\begin{array}{l}\text { Ranitidine (8), Amoxicillin- } \\
\text { Clavulanic acid (5), Carbamazepine } \\
\text { (2), Ibuprofen (2), Ondansetron (2), } \\
\text { Phenytoin (2), Vancomycin (2), } \\
\text { Amoxicillin (1), Cefadroxil (1), } \\
\text { Cefixime (1), Ceftriaxone (1), } \\
\text { Dicyclomine (1), Drotaverine (1), } \\
\text { Gentamicin (1), Meropenem (1), } \\
\text { Phenobarbitone (1), Piperacillin- } \\
\text { Tazobactam (1), Prednisolone (1) }\end{array}$ \\
\hline Local blister & $2(2.2)$ & $10(18.2)$ & $12(10.2)$ & BCG (12) \\
\hline Nausea and vomiting & $3(4.8)$ & $3(5.5)$ & $6(5.1)$ & $\begin{array}{l}\text { Azithromycin (1), Cefadroxil (1), } \\
\text { Cefotaxime (1), Cefpodoxime (1), } \\
\text { Ceftriaxone (1), Prednisolone (1) }\end{array}$ \\
\hline Diarrhoea & $4(6.3)$ & $2(3.6)$ & $6(5.1)$ & $\begin{array}{l}\text { Ceftriaxone (2), Amoxicillin- } \\
\text { Clavulanic acid (1), Cefpodoxime } \\
\text { (1), Levofloxacin (1), Linezolid (1) }\end{array}$ \\
\hline $\begin{array}{l}\text { Lab abnormalities, } \\
\text { DRESS syndrome }\end{array}$ & $0(0)$ & $4(7.3)$ & $4(3.4)$ & $\begin{array}{l}\text { Levetiracetam (2), Lamotrigine (1), } \\
\text { Phenytoin (1) }\end{array}$ \\
\hline Giddiness & $0(0)$ & $3(5.4)$ & $3(2.5)$ & Carbamazepine (2), Prednisolone (1) \\
\hline WDPV, vulval oedema & $0(0)$ & $3(5.4)$ & $3(2.5)$ & Levetiracetam (2), Lamotrigine (1) \\
\hline $\begin{array}{l}\text { Constipation, } \\
\text { Blurring of vision, } \\
\text { Difficulty in walking }\end{array}$ & $0(0)$ & $2(3.6)$ & $2(1.7)$ & Carbamazepine (2) \\
\hline Tremors of hands & $1(1.6)$ & $0(0)$ & $1(0.8)$ & Salbutamol (1) \\
\hline Blisters on ear & $1(1.6)$ & $0(0)$ & $1(0.8)$ & Drotaverine (1) \\
\hline $\begin{array}{l}\text { Increase in blood } \\
\text { pressure }\end{array}$ & $0(0)$ & $1(1.8)$ & $1(0.8)$ & Prednisolone (1) \\
\hline $\begin{array}{l}\text { Generalised painful } \\
\text { subcutaneous nodules, } \\
\text { Puffiness of face }\end{array}$ & $0(0)$ & $1(1.8)$ & $1(0.8)$ & Phenytoin (1) \\
\hline
\end{tabular}




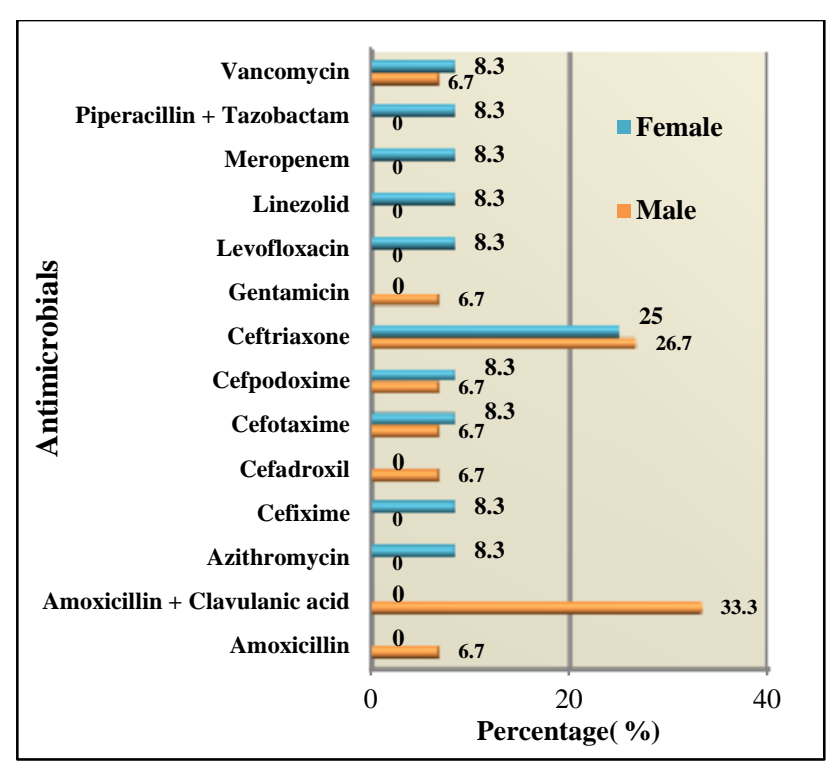

*Most common antibiotic which caused ADRs was ceftriaxone followed by amoxicillin-clavulanic acid.

\section{Figure 1: Antimicrobial agents causing ADRs.}

Figure 1 illustrates antimicrobial agents causing ADRs. Ceftriaxone was the most common (25.9\%) causing skin rash, pruritus, nausea, vomiting and diarrhoea which was followed by amoxicillin-clavulanic acid (generalised skin rash and pruritus and diarrhoea), cefotaxime (nausea and vomiting), cefpodoxime (nausea, vomiting and diarrhoea), vancomycin (generalised skin rash and pruritus), amoxicillin (generalised skin rash and pruritus), azithromycin (nausea and vomiting), cefixime (generalised skin rash and pruritus), cefadroxil (generalised skin rash, pruritus, urticaria, nausea and vomiting), gentamicin (generalised skin rash and pruritus), levofloxacin (diarrhoea), linezolid (diarrhoea), meropenem (generalised skin rash and pruritus) and piperacillin-tazobactam (generalised skin rash and pruritus) (Table 1).

Among antiepileptics, carbamazepine (CBZ) (2 females), levetiracetam (twice in the same female child), phenobarbitone ( 2 females) and phenytoin (1 male, 1 female child) contributed $22.2 \%$ each of ADRs. Lamotrigine was implicated in 1 female child (11.1\%). CBZ caused generalised skin rash, pruritus, constipation, giddiness, blurring of vision and ataxia at normal therapeutic doses. Phenytoin, levetiracetam and lamotrigine caused drug induced eosinophilia and systemic symptoms (DRESS syndrome). Additionally, levetiracetam and lamotrigine caused vulval oedema, white discharge per vagina (WDPV) and vaginitis. Phenytoin caused painful subcutaneous nodules and puffiness of face. Laboratory abnormalities were reversible and included leucocytosis, eosinophilia and elevated liver enzymes (Table 1).

Antiemetic, ondansetron caused generalised skin rash, pruritus and swelling of lips (1 male, 1 female child). Drug used in acid peptic disease, ranitidine caused generalised skin rash and pruritus in 3 male and 5 female children ( 8 in total). NSAID, ibuprofen caused generalised skin rash, pruritus and swelling of lips in 2 female children. Among antispasmodics, drotaverineinduced generalised skin rash, pruritus and vesicles on ears (1 male child) and dicyclomine-induced generalised skin rash and pruritus (1 female child) were reported. Bronchodilator, salbutamol caused hand tremors (1 female child). Steroidal preparation, prednisolone induced generalised skin rash, pruritus, nausea, vomiting, increase in blood pressure and giddiness ( 1 female child) (Table 1).

Causality was assessed by WHO causality and Naranjo's probability scale. Majority of ADRs were probable occurring in $109(92.4 \%)$ - 61 (96.8\%) males, 48 (87.3\%) females, followed by possible in 7 (5.9\%) and certain/definite in $2(1.7 \%)$ children. There were no ADRs of unlikely, conditional/unclassified and unassessable/unclassifiable causality according to WHO scale or doubtful according Naranjo's scale.

Severity of ADRs was assessed based on Modified Hartwig scale wherein $87(73.7 \%)$ were of moderate severity - 56 (88.9\%) males, 31 (56.4\%) females followed by mild in 27 (22.9\%) and severe in 4 (3.4\%). No deaths were reported in our study. Preventability of suspected ADRs was assessed by Modified Schumock and Thornton criteria and $72(61 \%)$ were definitely preventable - 42 (66.7\%) males, $30(54.5 \%)$ females, followed by not preventable in $30(25.4 \%)$ and probably preventable in 16 (13.6\%).

\section{DISCUSSION}

Monitoring of ADRs in paediatric population is as important as in adults. Despite various PV awareness activities, studies focusing on paediatric PV are lacking in India. Large cohort studies and systematic reviews from European countries including Germany, UK, and Italy and Shanghai from Asia have published reports of ADRs in children. According to a study done in Shanghai, the incidence of ADRs was $65.01 \%$ in children from 0-5 years. ${ }^{1}$ A qualitative review done by Aagard et al suggested that children of 1-10 years were at a greater risk of developing an ADR whereas other studies including large cohort studies in Germany, UK revealed that older children (11-18 years) were more likely to experience an ADR. ${ }^{12,13-16}$ However, there was no such association in certain studies. ${ }^{17}$ According to a 10 year study in UK, collective vaccine and non-vaccine reports suggested an overall increase among children <1 year. ${ }^{18}$ Majority of subjects in our study were in the age group of $0-1$ year. ${ }^{1,6,18}$ This could probably be due to the administration of vaccines in this age group.

Gender as one of the factors influencing the occurrence of ADRs has been a debate over the years. Few studies found female preponderance while certain others, no such correlation. ${ }^{1,3,6,13,14}$ In our study, however, there was male 
preponderance $(53.4 \%)$ which is consistent with an earlier documented report. ${ }^{12}$

The commonest ADRs were local site reactions (Table 1) which is in concordance with previous studies. According to a study done in Shanghai ${ }^{1}$ and a systematic review by Smyth et al large proportion of ADRs were local site reactions and mostly due to vaccines. ${ }^{3}$ Vaccine related studies by Choe et al in Korea and Aagard et al in Danish children reported the same. ${ }^{19,20}$
Skin is the most common organ involved in hypersensitivity to drugs and biological substances. $1,4,6,12$ In our study, skin reactions accounted for $91.5 \%$ which involved vaccine induced local site reactions (pain, redness, warmth, swelling and blister), drug induced rashes and pruritus. Rashes began during first week of treatment and resolved spontaneously without any sequelae (Table 2).

Table 2: Organ system affected.

\begin{tabular}{|c|c|c|c|c|c|c|}
\hline \multirow{3}{*}{ Organ system } & \multicolumn{6}{|c|}{ Gender n $(\%), \mathbf{n}=118$} \\
\hline & \multicolumn{2}{|c|}{ Male } & \multicolumn{2}{|c|}{ Female } & \multicolumn{2}{|c|}{ Total* } \\
\hline & $\mathbf{n}$ & $\%$ & $\mathbf{n}$ & $\%$ & $\mathbf{n}$ & $\%$ \\
\hline Skin & 58 & 92.1 & 50 & 90.9 & 108 & 91.5 \\
\hline Others $\dagger$ & 39 & 62.0 & 23 & 41.8 & 62 & 52.5 \\
\hline Gastrointestinal system & 5 & 7.9 & 7 & 12.7 & 12 & 10.2 \\
\hline Central nervous system & 1 & 1.6 & 3 & 5.5 & 4 & 3.4 \\
\hline Hepatobiliary system & 0 & 0 & 4 & 7.3 & 4 & 3.4 \\
\hline Genitourinary system & 0 & 0 & 3 & 5.5 & 3 & 2.5 \\
\hline Cardiovascular system & 0 & 0 & 1 & 1.8 & 1 & 0.8 \\
\hline
\end{tabular}

*Complaints overlap and total does not add up to $100 \%$. $†$ Others include excessive crying, refusal to feed and DRESS syndrome.

Table 3: ATC classification (level 1) of suspected drugs causing ADRs.

\begin{tabular}{|c|c|c|c|c|c|c|}
\hline \multirow{3}{*}{ Suspected drugs based on ATC } & \multicolumn{6}{|c|}{ Gender $\mathbf{n}(\%), \mathbf{n}=118$} \\
\hline & \multicolumn{2}{|c|}{ Male } & \multicolumn{2}{|c|}{ Female } & \multicolumn{2}{|c|}{ Total } \\
\hline & $\mathbf{n}$ & $\%$ & $\mathbf{n}$ & $\%$ & $\mathbf{n}$ & $\%$ \\
\hline Alimentary tract and metabolism (A) & 5 & 7.9 & 7 & 12.7 & 12 & 10.2 \\
\hline $\begin{array}{l}\text { Systemic hormonal preparations } \\
\text { excluding sex hormones and insulins }(\mathrm{H})\end{array}$ & 0 & 0 & 1 & 1.8 & 1 & 0.8 \\
\hline Anti-infectives for systemic use $(\mathrm{J})^{*}$ & 56 & 88.9 & 37 & 67.3 & 93 & 78.8 \\
\hline Musculoskeletal system (M) & 0 & 0 & 2 & 3.6 & 2 & 1.7 \\
\hline Nervous system $(\mathrm{N})$ & 1 & 1.6 & 8 & 14.6 & 9 & 7.6 \\
\hline Respiratory system (R) & 1 & 1.6 & 0 & 0 & 1 & 0.8 \\
\hline Total & 63 & 100 & 55 & 100 & 118 & 100 \\
\hline
\end{tabular}

*Anti-infectives for systemic use include antimicrobials and vaccines. †ADRs due to $\mathrm{J}$ were more commonly seen in males, whereas those due to $\mathrm{N}$ in females. There were no ADRs involving blood (B), dermatologicals (D), genitourinary and sex hormnes (G), antineoplastic and immunomodulating agents $(\mathrm{L})$, antiparasitics, insecticides and repellants $(\mathrm{P})$, sensory organs $(\mathrm{S})$ or various $(\mathrm{V})$.

Table 4: Therapeutic class of drugs causing ADRs.

\begin{tabular}{|c|c|c|c|c|c|c|}
\hline \multirow{3}{*}{ Therapeutic class } & \multicolumn{6}{|c|}{ Gender $\mathbf{n}(\%), \mathbf{n}=118$} \\
\hline & \multicolumn{2}{|c|}{ Male } & \multicolumn{2}{|c|}{ Female } & \multicolumn{2}{|c|}{ Total } \\
\hline & $\mathbf{n}$ & $\%$ & $\mathbf{n}$ & $\%$ & $\mathbf{n}$ & $\%$ \\
\hline Anti-emetics & 1 & 1.6 & 1 & 1.8 & 2 & 1.7 \\
\hline Anti-epileptics & 1 & 1.6 & 8 & 14.5 & 9 & 7.6 \\
\hline Antimicrobials & 15 & 23.8 & 12 & 21.8 & 27 & 22.9 \\
\hline Antispasmodics & 1 & 1.6 & 1 & 1.8 & 2 & 1.7 \\
\hline Bronchodilators & 1 & 1.6 & 0 & 0 & 1 & 0.8 \\
\hline Corticosteroids & 0 & 0 & 1 & 1.8 & 1 & 0.8 \\
\hline Drugs used in acid peptic disease & 3 & 4.8 & 5 & 9.2 & 8 & 6.9 \\
\hline NSAIDs & 0 & 0 & 2 & 3.6 & 2 & 1.7 \\
\hline Vaccines & 41 & 65.1 & 25 & 45.5 & 66 & 55.9 \\
\hline Total & 63 & 100 & 55 & 100 & 118 & 100 \\
\hline
\end{tabular}

*Vaccines and antimicrobials caused ADRs more among males whereas antiepileptics more in female children. 
ATC classification (level 1) was used to assess the system organ class of drugs causing ADRs. Majority of ADRs in the present study were due to anti-infectives (J) $(78.8 \%)$ which includes antimicrobials and vaccines (Table 3). This is consistent with previous studies. ${ }^{1,3,6}$ Vaccines (55.9\%) contributed to a large extent followed by antimicrobials $(22.9 \%))^{1,3,6,12,18}$ Drug classes according to ATC classification are divided into high-risk drugs (analgesics, antiepileptics, antibacterials, immunosuppressants, antimycotics and corticosteroids for systemic use) and low-risk drugs (others). ${ }^{13}$ In the present study, anti-infectives and antiepileptics were among the most common classes of drugs causing ADRs suggesting caution during prescription.

Most common vaccine implicated in ADRs in our study was $\mathrm{DPT}+\mathrm{HepB}+\mathrm{HiB}$ which is in concordance with previous studies followed by DPT $+\mathrm{HepB}$ and $\mathrm{BCG} .{ }^{19-21}$ "An adverse event following immunisation (AEFI) is a medical incident that takes place after immunisation, causes concern and is believed to be caused by immunisation". ${ }^{21}$ AEFI is classified into vaccination reaction, programme error, coincidental event, injection reaction and unknown events. ${ }^{21}$ Vaccines are responsible for over $50 \%$ of ADRs in children resulting in their inclusion in the list of possible causative agents. It has been reported that vaccine related ADRs are much higher than those due to other drugs. This reflects the high usage of vaccines in paediatrics compared to other medicines. ${ }^{21}$ Most common vaccines causing ADRs are: DT, hepatitis B vaccine (HBV), BCG, mumps measles rubella (MMR), $\mathrm{DPT}+\mathrm{HiB}$, pneumococcal vaccine, meningococcal C conjugate, human papilloma virus (HPV), DPT+IPV+HiB， DPT-IPV, OPV. 1,3,12,18,21,22 Most common ADRs seen with vaccines are pain, inflammation and infection at injection site, urticaria, angioedema, fever, vomiting, diarrhoea, irritability, rhinitis, cough and refusal of food among others. ${ }^{22}$ In our study, all 66 $(100 \%)$ children who received DPT $+\mathrm{HepB}+\mathrm{HiB}$ developed injection site pain, local redness, injection site warmth and injection site swelling whereas only 60 (90.9\%) developed fever and $54(81.8 \%)$ excessive crying and refusal to feed. Only 2 out of 12 children (16.7\%) who received BCG developed fever. This suggests that reactions following immunisation may not follow similar pattern among all children.

Among antimicrobials, ceftriaxone (25.9\%) was the most common offending agent in both males and females causing skin rash, pruritus, nausea, vomiting and diarrhoea. This is probably because it is the commonest antibiotic prescribed in our hospital setting in this age group. However, penicillins/cephalosporins, particularly amoxicillin-clavulanic acid, was the commonest according to a study. ${ }^{15}$

Among antiepileptics, CBZ, levetiracetam, phenobarbitone and phenytoin contributed to a large extent followed by lamotrigine. Our findings are similar to earlier reports. ${ }^{23-25}$ Levetiracetam, lamotrigine and phenytoin caused a serious reaction, DRESS syndrome in our study resulting in hospitalisation requiring intensive medical care. Lamotrigine and levetiracetam induced DRESS syndrome in an 18 year old girl who was a known case of partial seizures with secondary generalisation. Patient was put on lamotrigine (after she developed ADRs to phenobarbitone and CBZ) which caused DRESS syndrome. After drug withdrawal, she was discharged on levetiracetam to which she developed DRESS syndrome again and histopathological examination of skin suggested drug-induced hypersensitivity. Levetiracetam was discontinued, she recovered and was discharged on clobazam. Further, after months, she developed seizures for which her mother inadvertently administered levetiracetam and patient developed DRESS syndrome once again. She was hospitalised, recovered without any sequelae and discharged on clobazam. Phenytoin caused DRESS syndrome in another 18 year old girl. All were "definite" cases of DRESS syndrome according to RegiSCAR's scoring system. ${ }^{26}$ All instances of DRESS syndrome recovered after drug withdrawal. No deaths were reported in our study. ADRs due to antiepileptics can be common dose-dependent or serious idiosyncratic ADRs like maculopapular rash, erythroderma, fever, DRESS syndrome and SJS seen with phenobarbitone, phenytoin, CBZ, valproic acid and lamotrigine. Drugs most commonly associated with DRESS syndrome are antiepileptics, allopurinol, dapsone, minocycline, abacavir, nevirapine, aspirin and nitrofurantoin among others. $^{27}$ Although levetiracetam, different from other antiepileptics, was earlier known to be safe, cases of DRESS syndrome have been reported recently. ${ }^{23} \mathrm{We}$ report a rare case of levetiracetam induced DRESS syndrome in an 18 year old girl which according to the best of our knowledge is the first reported case in Indian subcontinent.

ADRs due to ondansetron, ranitidine and ibuprofen have been reported earlier. ${ }^{5,28,29}$ Although studied largely in adults, sufficient data regarding ADRs to NSAIDs in children is lacking. Lately, an increase in ibuprofen prescription has been reported among children for fever as compared to paracetamol. ${ }^{14}$ In our study, ibuprofen caused generalised skin rash, pruritus and swelling of lips similar to earlier studies. ${ }^{5,2829}$ At an antipyretic dose, it may cause skin rash, respiratory and gastrointestinal effects including haematemesis. ${ }^{27,30}$

Drotaverine and dicyclomine caused minor reactions. Antispasmodic drugs used in children for overactive bladder are usually oxybutynin and tolterodine. Studies report minor adverse effects like fever, and decrease in sweating. ${ }^{31}$ Salbutamol and prednisolone related reactions occurred at normal therapeutic doses. Bronchodilators cause tachycardia, tremor, nervousness, vomiting, dizziness, irritability, and various central nervous system manifestations. Skin rashes, gastric irritation and Cushing's syndrome are generally reported reactions due to corticosteroids. ${ }^{27}$ 
Large numbers of ADRs were probable in causality which is consistent with a previous study followed by possible and certain/definite. The two cases which were assessed as certain/definite were ADRs due to cefixime and levetiracetam, both in female patients. ${ }^{6}$ Cefixime caused generalised skin rash and pruritus. Levetiracetam caused DRESS syndrome resulting in hospitalisation of the patient. In both cases, the drugs were administered inadvertently despite previous ADR. Recovery was noted following drug withdrawal without any sequelae.

Majority were of moderate severity followed by mild and severe which was similar to a previous study. ${ }^{6}$ Four cases were reported as severe - DRESS syndrome due to levetiracetam (2), lamotrigine (1) and phenytoin (1) resulting in hospitalisation requiring intensive medical care. All cases recovered without any sequelae. No deaths were reported in our study.

Majority of ADRs (61\%) in our study were definitely preventable. These reactions were largely due to vaccines which are administered for protection against preventable diseases and it would be inappropriate to avoid future administration due to previous mild injection site reactions and fever. However, cefixime and levetiracetam associated reactions could have been averted by taking adequate history and proper counselling of family respectively. Our finding is in contrast to a study which reported most ADRs to be probably preventable. ${ }^{6}$

Our study sample size is less. We could not collect data of total number of patients exposed to a particular drug that caused an ADR which would have aided in calculating the incidence rate. Spontaneous ADR reporting practices could have been improved with continued ADR awareness and motivational programmes.

\section{CONCLUSION}

In our study, skin was the most common organ involved and anti-infectives $(\mathrm{J})$ were the main offending drugs. Clinical spectrum ranged from the more common and mild injection site reactions to severe DRESS syndrome requiring hospitalisation. Here, we report a rare case of levetiracetam induced DRESS syndrome which to the best of our knowledge is the first reported case in India. No fatalities were reported. Majority of ADRs were probable, moderate and definitely preventable. Children, being a vulnerable group, are prone to ADR related morbidity and mortality and therefore, a high level of caution needs be exercised while prescribing drugs. Paediatric PV is still in its infancy in India and an exaggerated surveillance is the need of the hour. In most centres, ADR reporting is essentially active and hence, healthcare professionals should be sensitised regarding spontaneous reporting by conducting regular awareness programmes. Furthermore, they should be educated to ensure early detection and treatment of ADRs which can preclude long term effects in children.

\section{ACKNOWLEDGEMENTS}

Author would like to thank the Department of Paediatrics, Kempegowda Institute of Medical Sciences, Bangalore, Karnataka, India.

Funding: No funding sources

Conflict of interest: None declared

Ethical approval: The study was approved by the Institutional Ethics Committee

\section{REFERENCES}

1. Li H, Guo X, Ye X, Jiang H, Du W, Xu J, et al. Adverse drug reactions of spontaneous reports in shanghai paediatric population. PLoS ONE 2014;9(2):1-6.

2. World Health Organization. Glossary of terms used in pharmacovigilance. Available at http://whoumc.org/Graphics/24729.pdf. Assessed on 28 May 2016.

3. Smyth RMD, Gargon E, Kirkham J, Cresswell L, Golder S, Smyth R, et al. Adverse drug reactions in children - a systematic review. PLoS ONE. 2012;7(3):1-24.

4. Napoleone E. Children and ADRs (adverse drug reactions). Ital J Pediatr. 2010;36:1-5.

5. Titchen T, Cranswick N, Beggs S. Adverse drug reactions to non-steroidal anti-inflammatory drugs, COX-2 inhibitors and paracetamol in a paediatric hospital. Br J Clin Pharmacol. 2005;59(6):718-23.

6. Priyadharsini R, Surendiran A, Adithan C, Sreenivasan S, Sahoo FK. A study of adverse drug reactions in paediatric patients. $\mathrm{J}$ Pharmacol Pharmacother. 2011;2(4):277-80.

7. WHO collaborating centre for drug statistics methodology. ATC/DDD Index, 2014. Available at http://www.whocc.no/atc_ddd_index/. Assessed on 28 May 2016.

8. World Health Organization (WHO) - Uppsala Monitoring Centre. The use of the WHO-UMC system for standardized case causality assessment. Available at http://who-umc.org/Graphics/24734.pdf. Assessed on 28 May 2016.

9. Naranjo CA, Busto U, Sellers EM. A method for estimating the probability of adverse drug reactions. Clin Pharmacol Ther. 1981;30:239-45.

10. Hartwig SC, Siegel J, Schneider PJ. Preventability and severity assessment in reporting adverse drug reactions. Am J Hosp Pharm. 1992;49:2229-32.

11. Schumock GT, Thornton JP. Focusing on the preventability of adverse drug reactions. Hosp Pharm. 1992;27:538.

12. Aagaard L, Christensen A, Hansen EH. Information about adverse drug reactions reported in children: a qualitative review of empirical studies. $\mathrm{Br} \mathrm{J}$ Clin Pharmacol. 2010;70(4):481-91.

13. Rashed AN, Wong ICK, Cranswick N, Tomlin S, Rascher W, Neubert A. Risk factors associated with adverse drug reactions in hospitalised children: 
international multicentre study. Eur J Clin Pharmacol. 2011;68:801-10.

14. Oehme AK, Rashed AN, Hefele B, Wong ICK, Rascher W. Adverse drug reactions in hospitalised children in Germany are decreasing: results of a nine year cohort-based comparison. PLoS ONE. 2012;7(9):1-11.

15. Gallagher RM, Mason JR, Bird KA, Kirkham JJ, Peak M, Williamson PR, et al. Adverse drug reactions causing admission to a paediatric hospital. PLoS ONE. 2012;7(12):1-8.

16. Thiesen S, Conroy EJ, Bellis JR, Bracken LE, Mannix HL, Bird KA, et al. Incidence, characteristics and risk factors of adverse drug reactions in hospitalised children - a prospective observational cohort study of 6,601 admissions. BMC Med. 2013;11:1-10.

17. Oshikoya KA. Adverse drug reactions in children: types, incidence, and risk factors. Niger $\mathrm{J}$ Paediatr. 2006;33(2):29-35.

18. Hawcutt DB, Mainie P, Riordan A, Smyth RL, Pirmohamed M. Reported paediatric adverse drug reactions in the UK 2000-2009. Br J Clin Pharmacol. 2011;73(3):437-46.

19. Choe YJ, Bae G. Management of vaccine safety in Korea. Clin Exp Vaccine Res. 2013;2:40-5.

20. Aagaard L, Hansen EW, Hansen EH. Adverse drug reactions following immunisation in Danish children: retrospective analysis of spontaneous reports submitted to the Danish Medicines Agency. Science against Microbial Pathogens: Communicating Current Research and Technological Advances. 2011;1:407-13.

21. Park K. Principles of epidemiology and epidemiological methods. In: Park K, editor. Park's textbook of preventive and social medicine, $20^{\text {th }}$ ed. Jabalpur: Banarsidas Bhanot Publishers; 2009:49122.

22. Arencibia ZB, Leyva AL, Pena YM, Reyes ARG, Manzano EF, Choonara I. Pharmacovigilance in children in Camaguey Province, Cuba. Eur J Clin Pharmacol. 2012;68:1079-84.

23. Gómez-Zorrilla S, Ferraz AV, Pedrós C, Lemus M, Peña C. Levetiracetam-induced drug reaction with eosinophilia and systemic symptoms syndrome. Ann Pharmacother. 2012;46(7-8):e20.

24. Crepeau AZ, Moseley BD, Wirrell EC. Specific safety and tolerability considerations in the use of anticonvulsant medications in children. Drug Healthc Patient Saf. 2012;4:39-54.

25. Karimzadeh P, Bakrani V. Antiepileptic drug-related adverse reactions and factors influencing these reactions. Iran J Child Neurol. 2013;7(3):23-7.

26. Cacoub P, Musette P, Descamps V, Meyer O, Speirs C, Finzi L, Roujeau JC. The DRESS Syndrome: A Literature Review. Amer J Med. 2011;124:588-97.

27. Boguniewicz M, Leung DYM. Adverse reactions to drugs. In: Kliegman RM, Stanton BF, Geme JW, Schor NF, Behrman RE, editors. Nelson textbook of paediatrics, $19^{\text {th }}$ ed. New Delhi: Saunders Elsevier Thomson Press; 2011:824-8.

28. Posthumus AA, Alingh CC, Zwaan CC, van Grootheest KK, Hanff LL, Witjes BB, et al. Adverse drug reaction-related admissions in paediatrics, a prospective single-centre study. Br Med J Open. 2012;2(4):1-6.

29. Kidon MI, Kang LW, Chin CW, Hoon LS, Hugo VB. Nonsteroidal anti-inflammatory drug hypersensitivity in preschool children. Allergy Asthma Clin Immunol. 2007;3:114-22.

30. Bianciotto M, Chiappini E, Raffaldi I, Gabiano C, Tovo P, Sollai S, et al. Drug use and upper gastrointestinal complications in children: a casecontrol study. Arch Dis Child. 2013;98:218-21.

31. Bansal V, Medhi B, Prakash O, Kaur B, Narasimhan KL. Tolerance of bladder antispasmodics in children with urinary incontinence: an observational study from North India. Indian $\mathbf{J}$ Pharmacol. 2011;43(6):744-5.

Cite this article as: Divyalasya TVS, Krishnaiah V, Yashoda HT, Pundarikaksha HP, Kudagi BL, Pathapati R. Adverse drug reactions in paediatric patients in a tertiary care hospital in India: a prospective observational single centre study. Int $\mathbf{J}$ Basic Clin Pharmacol 2016;5:2130-7. 